\title{
Alternatively activated macrophages are associated with the a2AP production that occurs with the development of dermal fibrosis
}

\section{The role of alternatively activated macrophages on the development of fibrosis}

\author{
Yosuke Kanno ${ }^{1,2^{*}}$, En Shu², Hirofumi Niwa², Hiroyuki Kanoh² and Mariko Seishima²
}

\begin{abstract}
Background: Fibrotic diseases are characterized by tissue overgrowth, hardening, and/or scarring because of the excessive production, deposition, and contraction of the extracellular matrix (ECM). However, the detailed mechanisms underlying these disorders remain unclear. It was recently reported that a2-antiplasmin (a2AP) is elevated in fibrotic tissue and that it is associated with the development of fibrosis. In the present study, we examined the mechanism underlying the production of a2AP on the development of fibrosis.
\end{abstract}

Methods: To clarify the mechanism underlying the production of a2AP on the development of fibrosis, we focused on high-mobility group box 1 (HMGB1), which is associated with the development of fibrosis. The mouse model of bleomycin-induced fibrosis was used to evaluate the production of a2AP on the development of fibrosis.

Results: We found that HMGB1 induced the production of a2AP through receptor for advanced glycation end products (RAGE) in fibroblasts. Next, we showed that macrophage reduction by a macrophage-depleting agent, clodronate, attenuated the progression of fibrosis and the production of a2AP and HMGB1 in the bleomycininduced mice. We also showed that IL-4-stimulated alternatively activated macrophages induced the production of HMGB1, that IL-4-stimulated alternatively activated macrophage conditioned media (CM) induced pro-fibrotic changes and a2AP production, and that the inhibition of HMGB1 and RAGE attenuated these effects in fibroblasts. Furthermore, the blockade of IL-4 signaling by IL-4Ra neutralizing antibodies attenuated the progression of fibrosis and the production of a2AP and HMGB1 in the bleomycin-induced mice.

(Continued on next page)

\footnotetext{
* Correspondence: ykanno@dwc.doshisha.ac.jp

'Department of Clinical Pathological Biochemistry, Faculty of Pharmaceutical Science, Doshisha Women's College of Liberal Arts, 97-1 Kodo Kyo-tanabe, Kyoto 610-0395, Japan

2Department of Dermatology, Graduate School of Medicine, Gifu University,

1-1 Yanagido, Gifu 501-1194, Japan
}

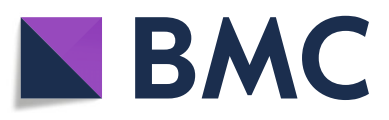

(c) The Author(s). 2020 Open Access This article is licensed under a Creative Commons Attribution 4.0 International License, which permits use, sharing, adaptation, distribution and reproduction in any medium or format, as long as you give appropriate credit to the original author(s) and the source, provide a link to the Creative Commons licence, and indicate if changes were made. The images or other third party material in this article are included in the article's Creative Commons licence, unless indicated otherwise in a credit line to the material. If material is not included in the article's Creative Commons licence and your intended use is not permitted by statutory regulation or exceeds the permitted use, you will need to obtain permission directly from the copyright holder. To view a copy of this licence, visit http://creativecommons.org/licenses/by/4.0/ The Creative Commons Public Domain Dedication waiver (http://creativecommons.org/publicdomain/zero/1.0/) applies to the data made available in this article, unless otherwise stated in a credit line to the data. 
(Continued from previous page)

Conclusion: These findings suggest that alternatively activated macrophage-derived HMGB1 induced the production of a2AP through RAGE and that these effects are associated with the development of fibrosis. Our findings may provide a clinical strategy for managing fibrotic disorders.

Keywords: Fibrosis, a2AP, HMGB1, Alternatively activated macrophages, IL-4Ra

\section{Introduction}

Fibrotic diseases are characterized by tissue overgrowth, hardening, and/or scarring due to excessive production, deposition, and contraction of the extracellular matrix (ECM). This process usually occurs over many months and years, and can lead to organ dysfunction or death. It has been reported that immune cells, such as alternatively activated macrophages, $\mathrm{T}$ cells, and $\mathrm{B}$ cells, have been found in the tissues with fibrotic disease and that immune cells induce the production of pro-fibrotic factors and ECM [1-5]. Although abnormality of the innate and adaptive immune systems induced by the increase in these immune cell numbers may contribute to the development of fibrosis, the detailed mechanism remains unclear.

Alpha2-antiplasmin ( $\alpha 2 \mathrm{AP}$ ) is known to be the principal inhibitor of plasmin, resulting in the formation of a stable inactive complex, plasmin- $\alpha 2 \mathrm{AP}$ (PAP), and inhibits fibrinolysis and ECM degradation [6-8]. $\alpha 2 \mathrm{AP}$ is synthesized in various tissues; has various functions, such as cytokine production, cell growth, and cell differentiation; and regulates angiogenesis, inflammatory response, immune modulation, tissue repair, bone formation, and brain functions [9-18]. Many studies have reported that the levels of PAP in plasma are elevated in fibrotic diseases which include systemic sclerosis (SSc), diabetic nephropathy, liver cirrhosis, and rheumatoid arthritis [19-22]. Recently, we showed that the expression of $\alpha 2 \mathrm{AP}$ is elevated in fibrotic tissue [11, 23-25], and $\alpha 2 \mathrm{AP}$ induces the transforming growth factor- $\beta$ (TGF- $\beta$ ) production through adipose triglyceride lipase (ATGL), which has been described as a member of the calcium-independent phospholipase $\mathrm{A}_{2}\left(\mathrm{iPLA}_{2}\right) /$ nutrin/patatin-like phospholipase domain-contain 2 (PNPLA2) family, and is associated with pro-fibrotic effects, such as cytokine production, myofibroblast differentiation, and ECM production [11, 26]. $\alpha 2 \mathrm{AP}$ also inhibits the activity of plasmin, which can directly and indirectly degrade a number of matrix proteins by activating latent metalloproteinases (MMPs) [8] and activate hepatocyte growth factor (HGF) [27, 28]. Furthermore, the blockade of $\alpha 2 \mathrm{AP}$ or $\alpha 2 \mathrm{AP}$ deficiency attenuates the development of fibrosis in humans and mice [11, $25,29]$, and the increase of $\alpha 2 \mathrm{AP}$ expression may play a critical role in the fibrotic disease severity. However, the mechanism underlying the production of $\alpha 2 \mathrm{AP}$ that occurs with the process of fibrosis progression remains unclear.
High-mobility group box 1 (HMGB1) is a multifunctional protein that exerts pro-inflammatory activity by mainly binding to receptor for advanced glycation end products (RAGE). It has been reported that HMGB1 is released from immune cells, and contributes to inflammation, immune responses, myofibroblast differentiation, ECM production, and fibrosis progression [3034], and the HMGB1 inhibitor, glycyrrhizin, attenuates the development of fibrosis in the belomycin-treated mice [35].

In the present study, we examined the mechanism underlying the production of $\alpha 2 \mathrm{AP}$ in the development of fibrosis and showed that alternatively activated macrophage-derived HMGB1 induced $\alpha 2 \mathrm{AP}$ production through RAGE in fibroblasts and that the blockade of IL-4 signaling by IL-4R $\alpha$ neutralization suppressed these effects, resulting in the improvement of fibrotic disorder.

\section{Methods}

\section{Mice experiment}

We induced dermal fibrosis in mice by bleomycin as previously described [29]. Bleomycin was dissolved in saline at $1 \mathrm{mg} / \mathrm{ml}$. The saline or bleomycin was administered subcutaneously into the shaved back of the mice (male 8-week-old SCID mice). The administration of saline or bleomycin in the same site was carried out daily for up to 2 weeks. In other experiments, the saline, bleomycin, saline plus clodronate (FormuMax Scientific, CA, USA), or bleomycin plus clodronate were similarly administered to the mice (male 8-week-old C57BL/6 J mice). The administration of saline or bleomycin in the same site was carried out daily for up to 2 weeks, and the administration of clodronate was carried out intraperitoneally every 3 days for up to 2 weeks. In addition, the saline or bleomycin was similarly administered to the mice (male 8-week-old C57BL/6 J mice). The administration of saline or bleomycin in the same site was carried out daily for up to 2 weeks, and the administration of control IgG $(2 \mathrm{mg} / \mathrm{kg})$ or anti-IL-4R $\alpha$ antibodies (2 $\mathrm{mg} / \mathrm{kg}$ ) (BD Biosciences, NJ, USA) was administered intraperitoneally every week for up to 2 weeks.

\section{Cell culture}

The dermal fibroblasts were obtained from mice as previously described [9]. The dermal fibroblasts or RAW 264.7 macrophages were seeded into the $35-\mathrm{mm}$ - 
diameter dishes and maintained in $2 \mathrm{ml}$ Dulbecco's modified Eagle's medium (DMEM) containing 10\% fetal calf serum (FCS) at $37^{\circ} \mathrm{C}$ in a humidified atmosphere with $5 \% \mathrm{CO}_{2} / 95 \%$ air. After 6 days, the medium was replaced with serum-free DMEM. Then, the cells were used for experiments. HMGB1 was obtained from Assaypro (MO, USA). Glycyrrhizin was obtained from Nacalai Tesque (Kyoto, Japan). FPS-ZM1 was obtained from Focus Biomolecules (PA, USA).

\section{Western blot analysis}

We performed a Western blot analysis as previously described [36]. Cells were washed twice with cold PBS, harvested, and then sonicated in lysis buffer containing $10 \mathrm{mM}$ Tris- $\mathrm{HCl}$ buffer (pH 7.5), 1\% SDS, $1 \%$ Triton X100 , and a protease inhibitor cocktail (Roche, Mannheim, Germany). The skin samples from mice were homogenized and sonicated in the lysis buffer. The protein concentration in each lysate was measured using a BCA protein assay kit (Pierce, IL, USA). Proteins in the supernatant were separated by electrophoresis on 10\% SDSpolyacrylamide gels and transferred to a PVDF membrane. We detected each protein by incubation with each antibody followed by incubation with horseradish peroxidase-conjugated antibodies to IgG. Anti-IL-4 antibody was obtained from Bioworld (MN, USA). AntiHMGB1 antibody and anti- $\alpha$-SMA antibody were obtained from Genetex (CA, USA). Anti-Arg-1 antibody was obtained from Proteintech (IL, USA). Anti- $\alpha 2 A P$ antibody and anti-RAGE antibody were obtained from Santa Cruz Biotechnology (CA, USA). Anti-type I collagen antibody was obtained from Bioss (MA, USA). AntiiNOS antibody was obtained from Anaspec (CA, USA). Anti-phospho-STAT6 antibody and anti-STAT6 antibody were obtained from Cusabio (TX, USA). AntiGAPDH antibody was obtained from Sigma-Aldrich (MO, USA).

\section{Measurement of dermal thickness}

The dermal thickness from the epidermal-dermal junction to dermal-subcutaneous junction was measured in skin sections, and it was determined by calculating the average of three-point measurement in each skin section. The measurements were carried out in a blinded fashion. The dermal thickness was measured in the skin sections from each group of mice.

\section{Sirius red staining}

Sirius red staining was performed as previously described [37]. After deparaffinization, the skin sections were treated with $0.2 \%$ phosphomolybdic acid for $5 \mathrm{~min}$. Next, the skin sections were stained with $0.1 \%$ sirius red for $90 \mathrm{~min}$ and $0.01 \mathrm{~N} \mathrm{HCl}$ for $2 \mathrm{~min}$.

\section{Immunohistochemical staining of $a-S M A$ and CD206}

Immunohistochemical staining of $\alpha$-SMA and CD206 was performed as previously described [38]. Paraffin sections of mice were labeled with anti- $\alpha$-SMA primary antibody (Genetex, CA, USA) or anti-CD206 primary antibody (R\&D systems, MN, USA), then secondarily labeled with Cy3-conjugated anti-rabbit IgG or FITCconjugated anti-goat IgG (Thermo Fisher Scientific, MA, USA), respectively. The signals were then detected using a laser-scanning microscope.

\section{siRNA study}

We performed siRNA study as previously described [39, 40]. The dermal fibroblasts were transfected with RAGE siRNA (Santa Cruz Biotechnology, CA, USA) using Lipofectamine 2000 (Invitrogen, CA, USA) according to the manufacturer's instructions. A non-specific siRNA was employed as the control. At $48 \mathrm{~h}$ after transfection, the cells were used for experiments.

\section{Statistical analysis}

All data were expressed as mean \pm SEM. The statistical analysis was conducted with unpaired $t$ test for twogroup comparison, with one-way ANOVA followed by the least significant difference test for multiple comparisons. Statistical significance was defined as a $P$ value of $<0.05$.

\section{Results \\ HMGB1 induced pro-fibrotic changes and a2AP production through RAGE in fibroblasts}

First, we focused on HMGB1, which is associated with the development of fibrosis, and found that HMGB1 induced pro-fibrotic changes, such as an increase in the expression of $\alpha$-smooth muscle actin ( $\alpha$-SMA) (a hallmark of the myofibroblast phenotype) and type I collagen, and $\alpha 2 \mathrm{AP}$ production in the dermal fibroblasts (Fig. 1a). It has been reported that HMGB1 can bind to RAGE, and mediates fibroblast activity and myofibroblast differentiation $[41,42]$. Therefore, we examined the effect of the RAGE-specific inhibitor FPS-ZM1 [43] on the HMGB1-induced pro-fibrotic effects and $\alpha 2 A P$ production in the dermal fibroblasts. FPS-ZM1 attenuated the HMGB1-induced pro-fibrotic changes and $\alpha 2 \mathrm{AP}$ production (Fig. 1b). Furthermore, we investigated the effect of RAGE reduction in dermal fibroblasts by using siRNA (Fig. 1c). The reduction of RAGE markedly attenuated the HMGB1-induced pro-fibrotic changes and $\alpha 2 A P$ production (Fig. 1d). These data suggest that HMGB1 induced pro-fibrotic changes and $\alpha 2 A P$ production through RAGE in fibroblasts. 


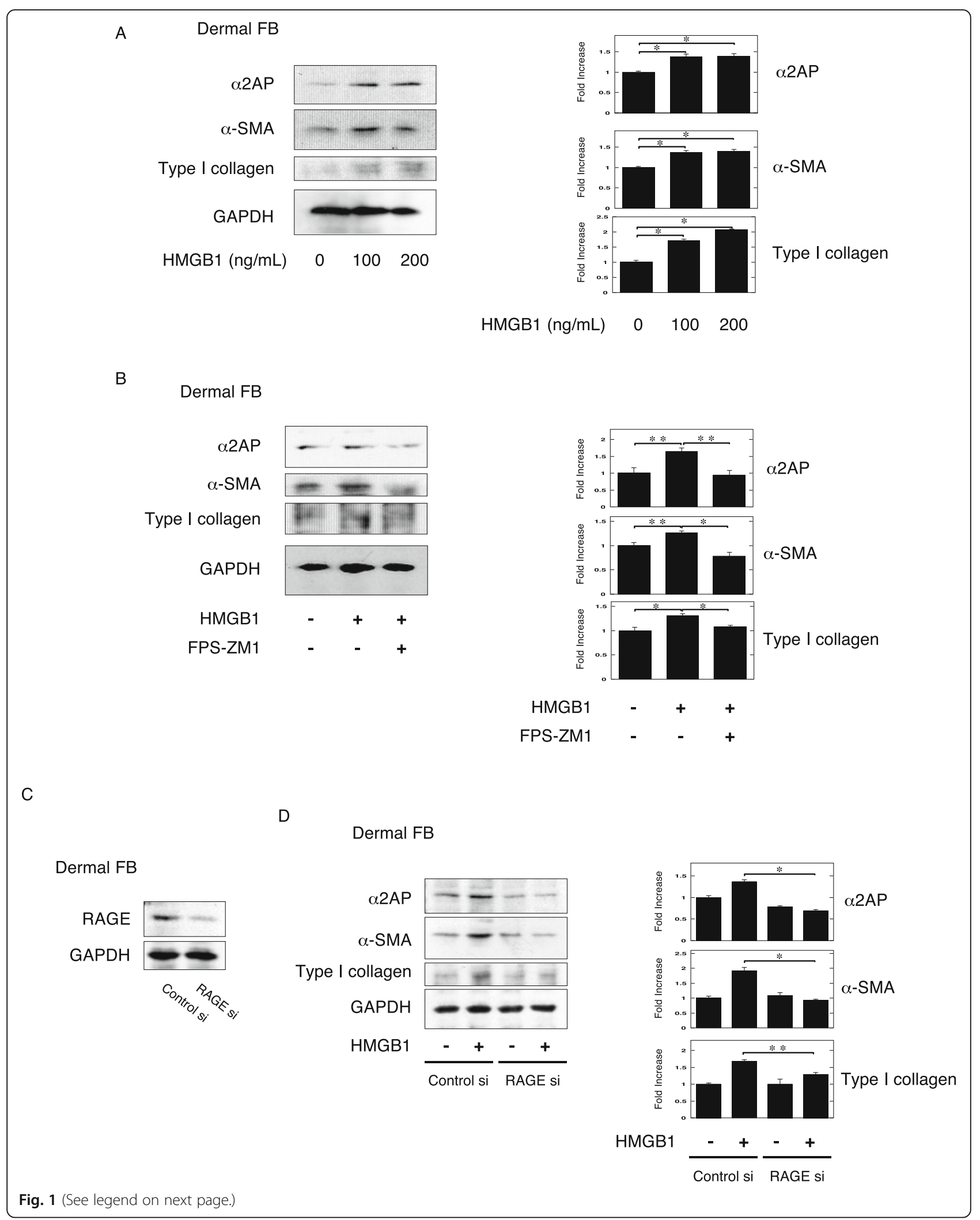


(See figure on previous page.)

Fig. $1 \mathrm{HMGB} 1$ induced pro-fibrotic changes and a2AP production through RAGE in fibroblasts. a The dermal fibroblasts were stimulated by HMGB1 $(100,200 \mathrm{ng} / \mathrm{ml})$ for $24 \mathrm{~h}$. The expression of each protein was examined by a Western blot analysis. The histogram shows quantitative representations of each protein $(n=3)$. b The dermal fibroblasts were pretreated by FPS-ZM1 $(100 \mu \mathrm{M})$ for 30 min and then stimulated by HMGB1 $(200 \mathrm{ng} / \mathrm{ml})$ for $24 \mathrm{~h}$. The expression of each protein was examined by a Western blot analysis. c The dermal fibroblasts were transfected with control or RAGE siRNA. At $48 \mathrm{~h}$ after transfection, the cells were used for experiments. $\mathbf{d}$ The siRNA-transfected dermal fibroblasts were stimulated by HMGB1 $(200 \mathrm{ng} / \mathrm{ml})$ for $24 \mathrm{~h}$. The expression of each protein was examined by a Western blot analysis. The histogram shows quantitative representations of each protein $(n=3)$. The data represent the mean \pm SEM. ${ }^{*} P<0.01,{ }^{*} P<0.05$

\section{The effects of immune cells on the development of fibrosis}

HMGB1 is released from immune cells, such as T cells, $B$ cells, macrophages, and the immune cells are associated with the development of fibrosis [4, 5]. Next, to clarify which immune cells are associated with the HMGB1 and $\alpha 2 \mathrm{AP}$ production that occurs with the development of fibrosis, we examined the effects of $\mathrm{T}$ and $B$ cells on belomycin-induced dermal fibrosis using $T$ and $\mathrm{B}$ cell-deficient severe combined immune deficiency (SCID) mice. The administration of bleomycin in SCID mice induced pro-fibrotic changes, such as increased dermal thickness (Fig. 2a, b) and an increase in the expression of type I collagen, $\alpha-S M A, I L-4, \alpha 2 A P$, HMGB1, inducible nitric oxide synthase (iNOS) (a hallmark of the classically activated macrophage phenotype), and Arg-1 and CD206 (Arg-1 and CD206; a hallmark of the alternatively activated macrophage phenotype) in the skin (Fig. 2c, d). Furthermore, we examined the effects of macrophage reduction by clodronate [44] on the fibrosis progression and the HMGB1 and $\alpha 2 \mathrm{AP}$ production. Macrophage reduction in the bleomycin-treated mice abolished the pro-fibrotic changes, such as increased dermal thickness (Fig. 3a, b) and an increase in the expression of type I collagen, $\alpha-S M A, \alpha 2 A P$, HMGB1, iNOS, and Arg-1 and CD206 in the skin (Fig. 3c, d). These data suggest that macrophages are associated with the HMGB1 and $\alpha 2 \mathrm{AP}$ production that occurs with the process of fibrosis progression.

\section{The effects of alternatively activated macrophages on the progression of fibrosis and the production of a2AP and HMGB1}

Alternatively activated macrophages are associated with the development of dermal fibrosis [45, 46]. Thus, we examined the effects of alternatively activated macrophages on fibrosis progression and the production of HMGB1 and $\alpha 2 A P$. Since IL- 4 is known to induce alternatively activated macrophages, we then confirmed that IL-4 induced an increase in the Arg-1 expression in RAW 264.7 macrophages (Fig. 4a). Next, we examined the effects of alternatively activated macrophages on the development of fibrosis and showed that conditioned media (CM) of IL-4-treated RAW264.7 macrophages induced the pro-fibrotic changes, such as an increase in the expression of $\alpha$-SMA, type I collagen, and $\alpha 2 \mathrm{AP}$ production in the dermal fibroblasts (Fig. 4b). In addition, we examined the effect of the direct HMGB1 inhibitor glycyrrhizin [47] and showed that glycyrrhizin attenuated the IL-4-treated RAW 264.7 macrophage CMinduced pro-fibrotic changes and $\alpha 2 \mathrm{AP}$ production in the dermal fibroblasts (Fig. 4c). Furthermore, we showed FPS-ZM1 attenuated the IL-4-treated RAW 264.7 macrophage CM-induced pro-fibrotic changes and $\alpha 2 \mathrm{AP}$ production in the dermal fibroblasts (Fig. 4d). These data suggest that IL-4-stimulated alternatively activated macrophages produced HMGB1 and that the HMGB1 induced pro-fibrotic changes and $\alpha 2 \mathrm{AP}$ production through RAGE in fibroblasts.

\section{The effects of IL-4Ra neutralization on the development of fibrosis}

Furthermore, to clarify whether IL-4 signaling is associated with the HMGB1 and $\alpha 2 \mathrm{AP}$ production that occurs with the development of fibrosis, we examined the effects of IL-4 blocking by IL-4 receptor $\alpha$ (IL-4R $\alpha$ ) neutralization in bleomycin-treated mice. The administration of IL-4R $\alpha$ neutralization antibodies to the bleomycin-treated mice attenuated the pro-fibrotic changes, such as increased dermal thickness (Fig. 5a, b) and an increase in the expression of type I collagen, $\alpha$ SMA, $\alpha 2$ AP, HMGB1, and Arg-1 and CD206 in the skin (Fig. 5c, d). In contrast, the IL-4R $\alpha$ neutralization did not attenuate an increase in the expression of iNOS in the skin (Fig. 5c). Furthermore, we showed that the administration of IL-4R $\alpha$ neutralization antibodies to the bleomycin-treated mice attenuated the STAT6 activation in the skin (Fig. 5c). These data suggest that IL-4 signaling is associated with the increase in alternatively activated macrophage numbers and the production of HMGB1 and $\alpha 2 \mathrm{AP}$ that occurs with the process of fibrosis progression.

\section{Discussion}

Fibrotic diseases are characterized by tissue overgrowth, hardening, and/or scarring due to the excessive production, deposition, and contraction of ECM. Recently, we showed that the expression of $\alpha 2 \mathrm{AP}$ is elevated in fibrotic tissue and that the blockade of $\alpha 2 \mathrm{AP}$ attenuates the development of fibrosis $[11,24,25] . \alpha 2 \mathrm{AP}$ is 


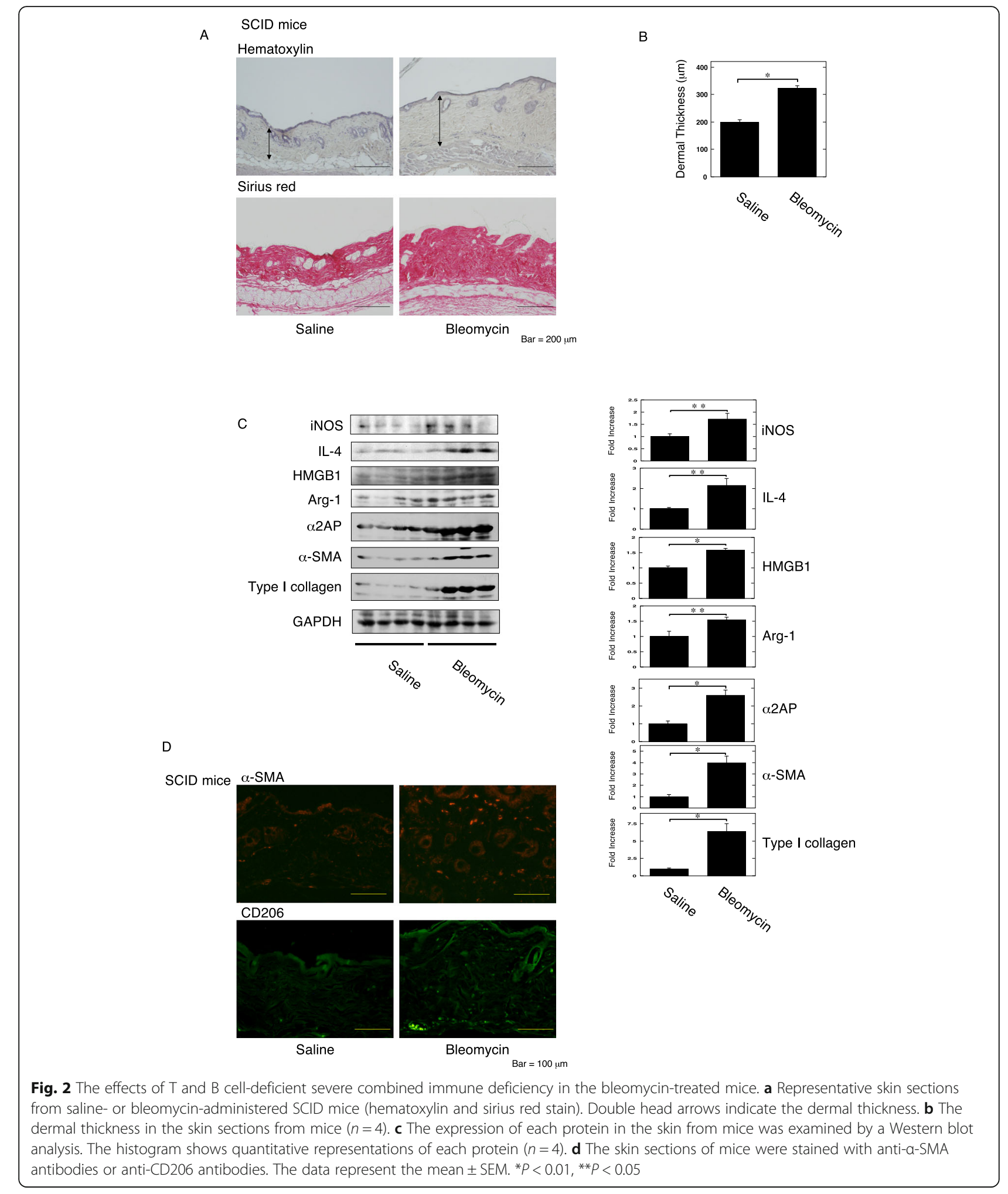

associated with the production of pro-fibrotic factors, myofibroblast differentiation, ECM production, and plasmin inhibition $[7,11,26]$, and increased $\alpha 2 A P$ may play an important role in the development of fibrosis. Thus, we examined the mechanism underlying the production of $\alpha 2 \mathrm{AP}$ that occurs with the development of fibrosis.

In this study, we focused on HMGB1, which is known to contribute to inflammation, immune response, 
A

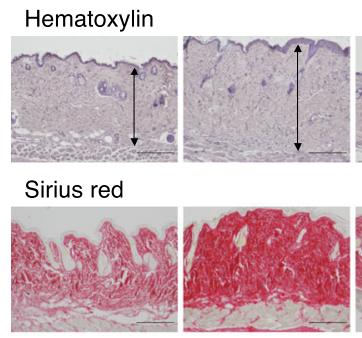

Saline

Bleomycin

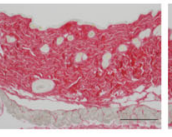

Saline +Clodronate
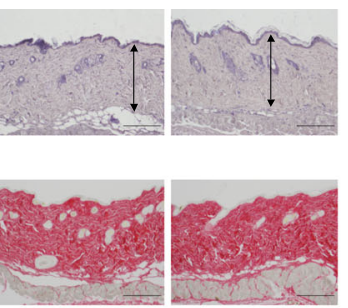

Bleomycin +Clodronate

$\mathrm{Bar}=200 \mu \mathrm{m}$
B

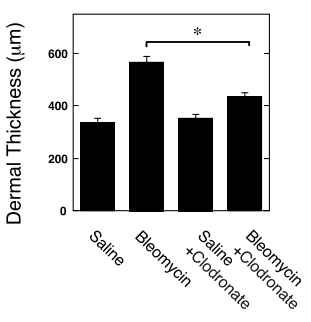

C

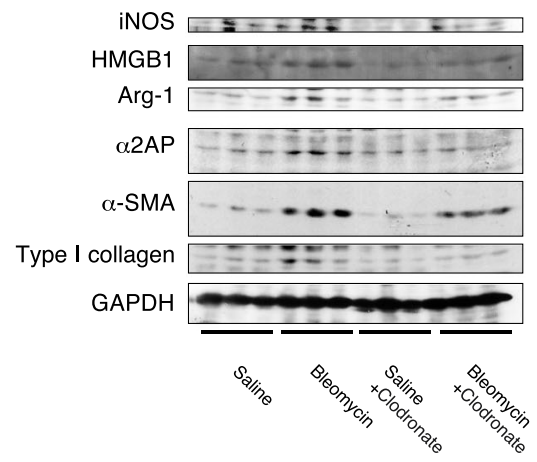

D

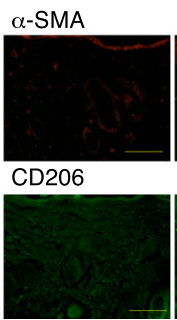

Saline
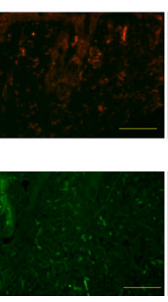

Bleomycin
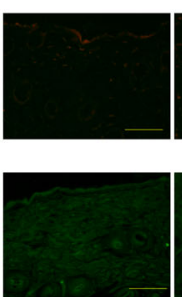
Saline
+ Clodronate

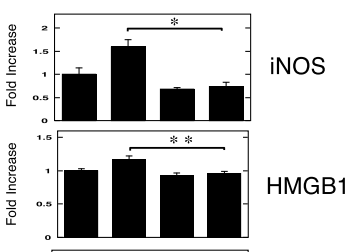

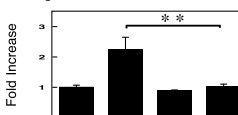

Arg-1

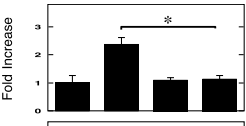

$\alpha 2 A P$

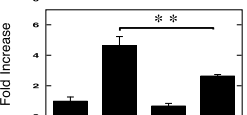

$\alpha-S M A$

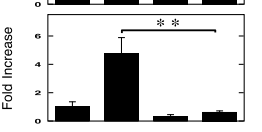

Type I collagen
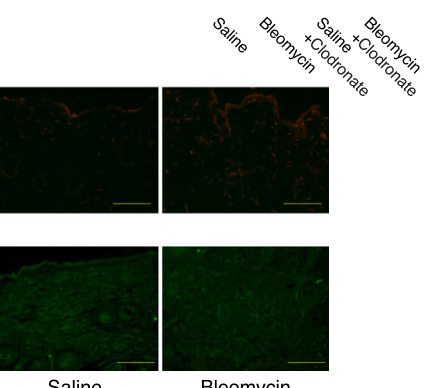

Bleomycin

+Clodronate

$\mathrm{Bar}=100 \mu \mathrm{m}$

Fig. 3 The effects of macrophage reduction in the bleomycin-treated mice. a Representative skin sections from saline-, bleomycin-, saline plus clodronate-, or bleomycin plus clodronate-administered mice (hematoxylin and sirius red stain). Double head arrows indicate the dermal thickness. $\mathbf{b}$ The dermal thickness in the skin sections from mice $(n=4)$. $\mathbf{c}$ The expression of each protein in the skin from mice was examined by a Western blot analysis. The histogram shows quantitative representations of each protein $(n=3)$. $\mathbf{d}$ The skin sections of mice were stained with anti-a-SMA antibodies or anti-CD206 antibodies. The data represent the mean \pm SEM. ${ }^{*} P<0.01,{ }^{*} P<0.05$

myofibroblast differentiation, ECM production, and progression of fibrosis [30-34], and found that HMGB1 induced pro-fibrotic changes and the production of $\alpha 2 \mathrm{AP}$ through RAGE in fibroblasts (Fig. 1). In addition, we showed that macrophage reduction attenuated the pro- fibrotic changes and the HMGB1 and $\alpha 2 \mathrm{AP}$ production that occurs with the process of fibrosis progression (Fig. 3). On the other hand, the pro-fibrotic changes and the HMGB1 and $\alpha 2 \mathrm{AP}$ production were induced in bleomycin-treated $\mathrm{T}$ and $\mathrm{B}$ cell-deficient SCID mice 
A RAW $264.7 \mathrm{M \phi}$

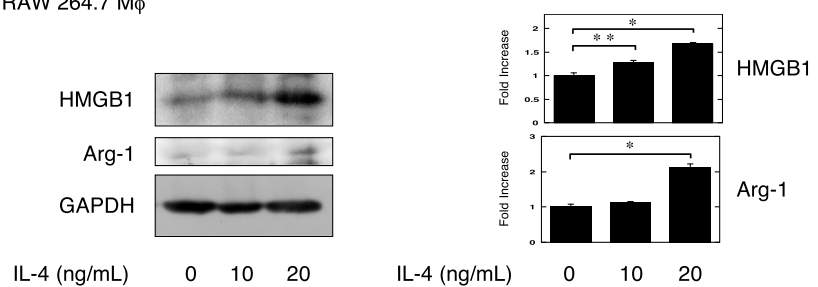

B

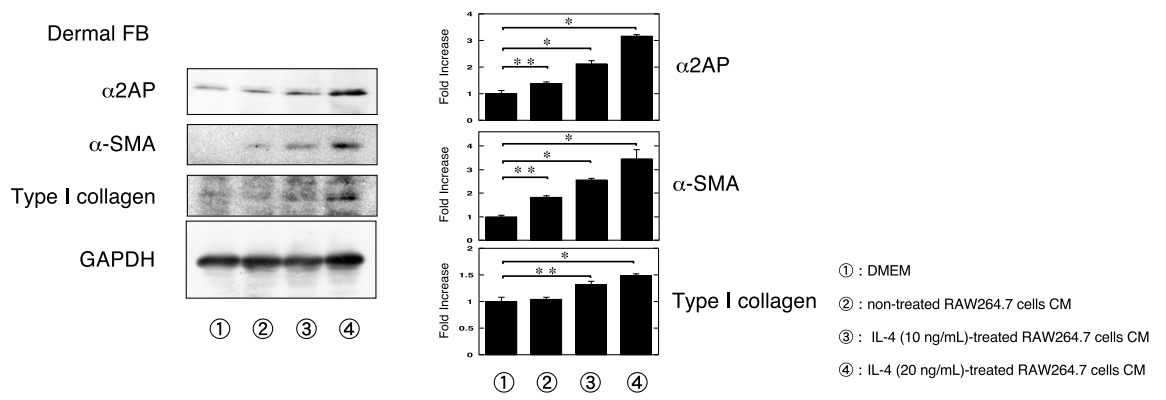

C

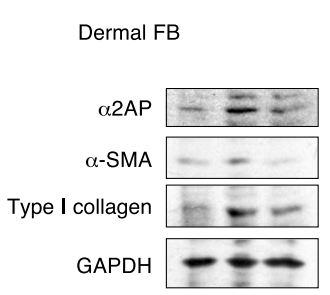

(1) (2) (3)

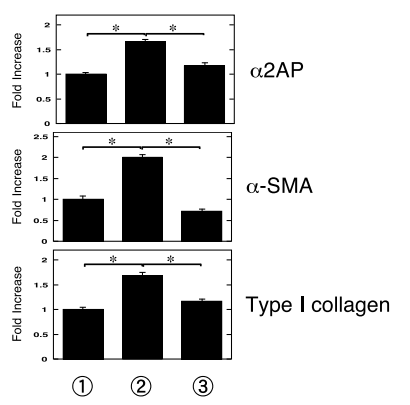

(1) : DMEM

(2) : IL-4 $(20 \mathrm{ng} / \mathrm{mL})$-treated RAW264.7 cells CM

(3) : IL-4 (20 ng/mL)-treated RAW264.7 cells CM +Glycyrrhizin

D Dermal FB

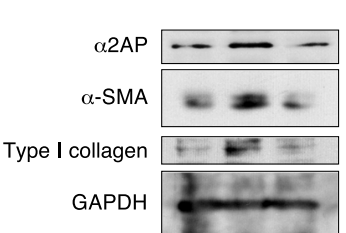

(1) (2) (3)

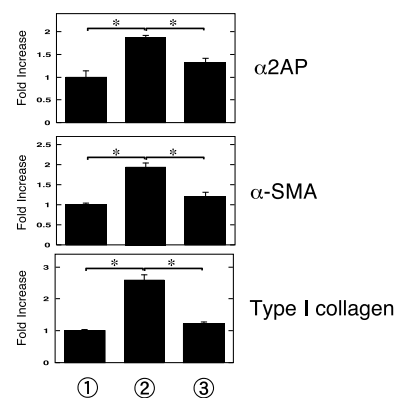

(1) : DMEM

(2) : IL-4 (20 ng/mL)-treated RAW264.7 cells CM

(3) : IL-4 (20 ng/mL)-treated RAW264.7 cells CM +FPS-ZM1

Fig. 4 The effects of alternatively activated macrophages on the progression of fibrosis and the production of a2AP and HMGB1. a RAW 264.7 macrophages were stimulated by IL-4 (10, $20 \mathrm{ng} / \mathrm{ml})$ for $48 \mathrm{~h}$. The expression of each protein was examined by a Western blot analysis. The histogram shows quantitative representations of each protein $(n=3)$. $\mathbf{b}$ The dermal fibroblasts were cultured with the CM of the non-treated RAW 264.7 cells, the IL-4 $(10 \mathrm{ng} / \mathrm{ml})$-treated RAW 264.7 cells, or the IL-4 $(20 \mathrm{ng} / \mathrm{ml})$-treated RAW 264.7 cells for $24 \mathrm{~h}$. The expression of each protein was examined by a Western blot analysis. The histogram shows quantitative representations of each protein $(n=3)$. c The dermal fibroblasts were cultured with the CM of the IL-4 (20 ng/ml)-treated RAW 264.7 cells supplemented with or without glycyrrhizin (100 $\mu \mathrm{gg} / \mathrm{ml})$ for $24 \mathrm{~h}$. The expression of each protein was examined by a Western blot analysis. The histogram shows quantitative representations of each protein $(n=3)$. $\mathbf{d}$ The dermal fibroblasts were treated with the CM of the IL-4 $(20 \mathrm{ng} / \mathrm{ml})$-treated RAW 264.7 cells supplemented with or without FPS-ZM1 $(200 \mu \mathrm{M})$ for $24 \mathrm{~h}$. The expression of each protein was examined by a Western blot analysis. The histogram shows quantitative representations of each protein $(n=3)$. The data represent the mean \pm SEM. ${ }^{*} P<0.01$, ${ }^{* *} P<0.05$ 
A

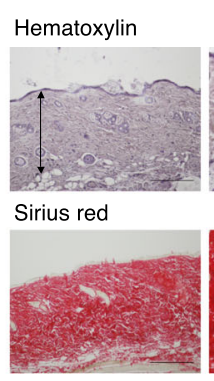

Saline
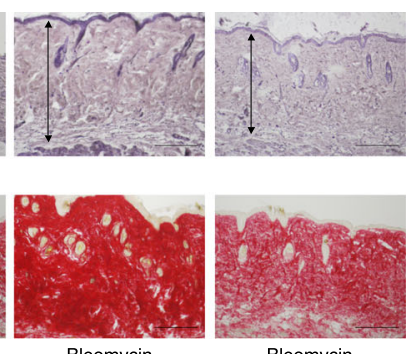

Bleomycin +Control IgG

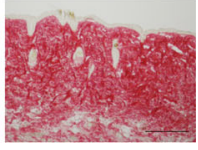

Bleomycin +Anti-IL-4R $\alpha$ antibody
B

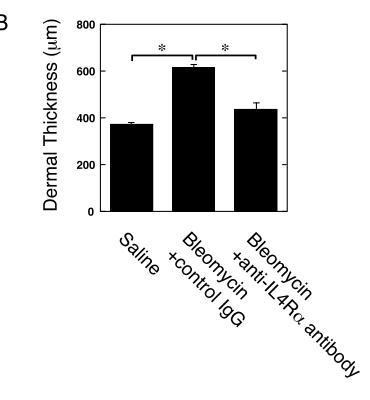

C

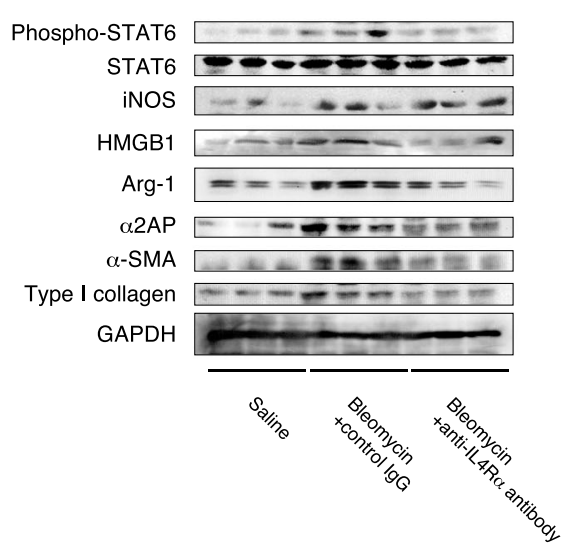

D
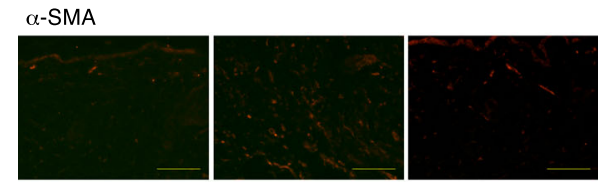

CD206

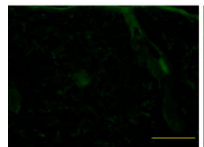

Saline

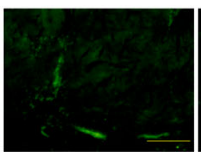

Bleomycin Bleomycin
+ Control lgG

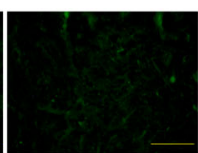

Bleomycin +Anti-IL-4R $\alpha$ antibody

$$
\mathrm{Bar}=200 \mu \mathrm{m}
$$

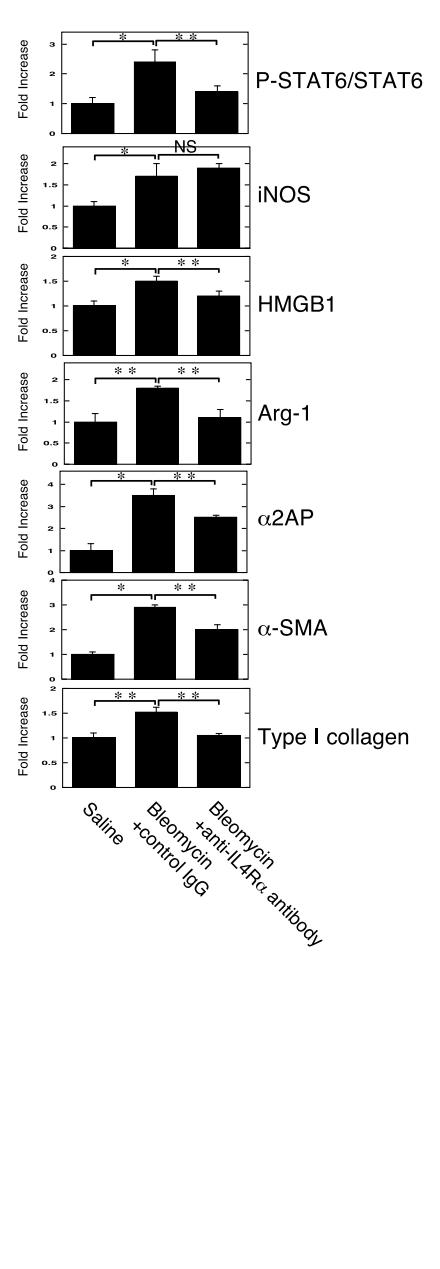

Fig. 5 The effects of IL-4Ra neutralization in the bleomycin-treated mice. a Representative skin sections from saline-, bleomycin plus control lgG-, or bleomycin plus IL-4Ra neutralizing antibodies-administered mice (hematoxylin and sirius red stain). Double head arrows indicate the dermal thickness. $\mathbf{b}$ The dermal thickness in the skin sections from mice $(n=4)$. $\mathbf{c}$ The expression of each protein in the skin from mice was examined by a Western blot analysis. The histogram shows quantitative representations of each protein $(n=3)$. $\mathbf{d}$ The skin sections of mice were stained with anti-a-SMA antibodies or anti-CD206 antibodies. The data represent the mean \pm SEM. ${ }^{*} P<0.01 .{ }^{* *} P<0.05$

(Fig. 2). Several studies have reported that $\mathrm{T}$ and $\mathrm{B}$ cells are not an essential requirement for the development of fibrosis $[48,49]$. These data suggest that macrophages may play a pivotal role in the process of fibrosis progression and that macrophage-regulated production of
HMGB1 and $\alpha 2$ AP may be associated with the induction and development of fibrosis.

HMGB1 is secreted by activated macrophages and is associated with the polarization of classically and alternatively activated macrophage and the promotion of 
cytokine production in alternatively activated macrophage [50-53]. It has been reported that classically and alternatively activated macrophages are associated with the induction and development of inflammation and fibrosis $[5,54]$. In particular, alternatively activated macrophages are elevated in SSc patients [55], and they are associated with the development of dermal fibrosis [45, 46]. In the present study, we showed that the expression of classically and alternatively activated macrophage markers was elevated in dermal fibrosis model mice. We also showed that the blockade of IL-4R $\alpha$ attenuated the pro-fibrotic changes and the increase in the expression of $\alpha 2 \mathrm{AP}$, HMGB1, and alternatively activated macrophage markers in dermal fibrosis model mice, but not the increase in the expression of classically activated macrophage markers. These data suggest that IL-4 signaling is associated with the increase in alternatively activated macrophage numbers and the production of HMGB1 and $\alpha 2 A P$ that occurs with the process of fibrosis progression. In addition, HMGB1 may not affect the increase in classically activated macrophage numbers in dermal fibrosis model mice, and classically activated macrophages may be not an essential requirement for the IL-4-mediated fibrosis progression. Next, we showed that IL-4-stimulated alternatively activated macrophages produced HMGB1 (Fig. 4a) and that the IL-4-stimulated alternatively activated macrophage $\mathrm{CM}$ induced profibrotic changes and the production of $\alpha 2 \mathrm{AP}$ through HMGB1/RAGE in fibroblasts (Fig. 4). On the other hand, IL-4 did not induce the production of HMGB1 in fibroblasts (data not shown). These data suggest that IL4-stimulated alternatively activated macrophages produced HMGB1, and the HMGB1 subsequently induced $\alpha 2 \mathrm{AP}$ production in fibroblasts.

The serum level of IL-4 is elevated in bleomycintreated mice $[56,57]$. We showed that IL-4 was elevated in bleomycin-treated $\mathrm{T}$ and $\mathrm{B}$ cell-deficient SCID mice skin (Fig. 2c). IL-4 is mainly produced by $\mathrm{T}$ cells but is also produced by mast cells, basophils, and eosinophils [58]. These cells may be associated with the production of IL-4, and the increase of IL-4 may cause the induction and development of fibrosis. IL-4 is also known to regulate macrophage proliferation and accumulation, and to induce collagen synthesis and fibroblast proliferation, and is associated with the development of fibrosis [5962]. Furthermore, we showed that the blockade of IL-4 signaling attenuated the pro-fibrotic changes, the increase in alternatively activated macrophage numbers, and the production of HMGB1 and $\alpha 2 \mathrm{AP}$ that occurred with the process of fibrosis progression (Fig. 5). In addition, the IL-4R $\alpha$ signaling regulates IL-4-induced STAT6 activation [63]. We showed that the blockade of IL-4R $\alpha$ attenuated the STAT6 activation in dermal fibrosis model mice. It has been reported that the inhibition of STAT6 causes the resolution of lung inflammation and fibrosis in the bleomycin-treated mice [64], and the STAT6 pathway is associated with bone marrow-derived fibroblast activation [65]. The attenuation of STAT6 by IL-4R $\alpha$ neutralizing may contribute to the development of dermal fibrosis. These data suggest that the IL-4 signaling plays an important role on the induction and development of fibrosis, and the blockade of IL-4 signaling may be a potential target for novel therapies that prevent fibrotic diseases.

\section{Conclusion}

Alternatively activated macrophage-derived HMGB1 induced the $\alpha 2 \mathrm{AP}$ production through RAGE, and these effects are associated with the development of fibrosis. Our findings may provide a novel therapeutic approach to the treatment of fibrotic disorder.

\section{Abbreviations}

a2AP: a2-Antiplasmin; a-SMA: a-Smooth muscle actin; ATGL: Adipose triglyceride lipase; CM: Conditioned media; DMEM: Dulbecco's modified Eagle's medium; ECM: Extracellular matrix; FCS: Fetal calf serum;

HGF: Hepatocyte growth factor; HMGB1: High-mobility group box 1; IL4Ra: IL-4 receptor $a_{\text {; }}$ iNOS: Inducible nitric oxide synthase; iPLA 2 : Calciumindependent phospholipase $\mathrm{A}_{2}$; MMPs: Metalloproteinases; PAP: Plasmina2AP; PNPLA2: Patatin-like phospholipase domain-contain 2; RAGE: Receptor for advanced glycation end products; SCID: Severe combined immune deficiency; SSc: Systemic sclerosis; TGF- $\beta$ : Transforming growth factor- $\beta$

\section{Acknowledgements}

We appreciate the support by the Takeda Science Foundation.

\section{Authors' contributions}

YK conceived and designed the experiment. YK, ES, HN, HK, and MS were involved in the experiments. YK, ES, HK, and MS were involved in the data interpretation and writing of the manuscript. The authors read and approved the final manuscript

\section{Funding}

This work was supported by the Takeda Science Foundation.

\section{Availability of data and materials}

The authors declare that all data supporting the findings of this study are available within the article.

\section{Ethics approval and consent to participate}

The animal experiments in this study were approved by the Animal Research Committee of Doshisha Women's College of Liberal Arts (approval ID: Y16028, Y18-022).

\section{Consent for publication}

All authors approved the manuscript for submission.

\section{Competing interests}

The authors declare that they have no competing interests.

Received: 30 September 2019 Accepted: 23 March 2020

Published online: 10 April 2020

\section{References}

1. Higashi-Kuwata $N$, Jinnin M, Makino T, Fukushima S, Inoue $Y$, Muchemwa FC, Yonemura Y, Komohara Y, Takeya M, Mitsuya H, Ihn H. Characterization of monocyte/macrophage subsets in the skin and peripheral blood derived from patients with systemic sclerosis. Arthritis Res Ther. 2010;12:R128.

2. O'Reilly $S$, Hügle T, van Laar JM. T cells in systemic sclerosis: a reappraisal. Rheumatology (Oxford). 2012;51:1540-9. 
3. Sanges $S$, Guerrier $T$, Launay $D$, Lefèvre $G$, Labalette $M$, Forestier $A$, Sobanski V, Corli J, Hauspie C, Jendoubi M, Yakoub-Agha I, Hatron PY, Hachulla E, Dubucquoi S. Role of B cells in the pathogenesis of systemic sclerosis. Rev Med Interne. 2017:38:113-24.

4. Wynn TA, Ramalingam TR. Mechanisms of fibrosis: therapeutic translation for fibrotic disease. Nat Med. 2012;18:1028-40.

5. Zhang L, Wang Y, Wu G, Xiong W, Gu W, Wang CY. Macrophages: friend or foe in idiopathic pulmonary fibrosis? Respir Res. 2018;19:170.

6. Collen D. Identification and some properties of a new fast-reacting plasmin inhibitor in human plasma. Eur J Biochem. 1976;69:209-16.

7. Kanno Y, Ishisaki A, Kawashita E, Kuretake H, Ikeda K, Matsuo O. uPA attenuated LPS-induced inflammatory osteoclastogenesis through the plasmin/PAR-1/Ca ${ }^{2+} /$ CaMKKAMPK Axis. Int J Biol Sci. 2016;12:63-71.

8. Eddy A. Serine proteases, inhibitors and receptors in renal fibrosis. Thromb Haemost. 2009:101:656-64

9. Kanno Y, Hirade K, Ishisaki A, Nakajima K, Suga H, Into T, Matsushita K, Okada K, Matsuo O, Matsuno H. Lack of alpha2-antiplasmin improves cutaneous wound healing via over-released vascular endothelial growth factor-induced angiogenesis in wound lesions. J Thromb Haemost. 2006;4: 1602-10.

10. Eddy JL, Schroeder JA, Zimbler DL, Bellows LE, Lathem WW. Impact of the Pla protease substrate a2-antiplasmin on the progression of primary pneumonic plague. Infect Immun. 2015:83:4837-47.

11. Kanno Y, Kawashita E, Kokado A, Kuretake H, Ikeda K, Okada K, Seishima M, Ueshima S, Matsuo O, Matsuno H. a2AP mediated myofibroblast formation and the development of renal fibrosis in unilateral ureteral obstruction. Sci Rep. 2014;4:5967.

12. Kawashita E, Kanno Y, Asayama H, Okada K, Ueshima S, Matsuo O, Matsuno $H$. Involvement of a2-antiplasmin in dendritic growth of hippocampal neurons. J Neurochem. 2013;126:58-69.

13. Kawashita E, Kanno Y, Ikeda K, Kuretake H, Matsuo O, Matsuno H. Altered behavior in mice with deletion of the alpha2-antiplasmin gene. PLoS One. 2014;9:e97947

14. Kanno Y, Ishisaki A, Kuretake H, Maruyama C, Matsuda A, Matsuo O. a2antiplasmin modulates bone formation by negatively regulating osteoblast differentiation and function. Int J Mol Med. 2017:40:854-8.

15. Okada K, Ueshima S, Kawao N, Yano M, Tamura Y, Tanaka M, Sakamoto A, Hatano M, Arima M, Miyata S, Nagai N, Tokuhisa T, Matsuo O. Lack of both a2-antiplasmin and plasminogen activator inhibitor type-1 induces high lgE production. Life Sci. 2013:93:89-95.

16. Hou Y, Okada K, Okamoto C, Ueshima S, Matsuo O. Alpha2-antiplasmin is a critical regulator of angiotensin II-mediated vascular remodeling. Arterioscler Thromb Vasc Biol. 2008;28:1257-62.

17. Menoud PA, Sappino N, Boudal-Khoshbeen M, Vassalli JD, Sappino AP. The kidney is a major site of alpha2-antiplasmin production. J Clin Invest. 1996; 97:2478-84.

18. Kanno $Y$, Shu E, Kanoh H, Matsuda A, Seishima M. a2AP regulates vascular alteration by inhibiting VEGF signaling in systemic sclerosis: the roles of a2AP in vascular dysfunction in systemic sclerosis. Arthritis Res Ther. 2017; 19:22.

19. Yagame M, Eguchi K, Suzuki D, Machimura H, Takeda H, Inoue W, Tanaka K, Kaneshige $\mathrm{H}$, Nomoto $Y$, Sakai $\mathrm{H}$. Fibrinolysis in patients with diabetic nephropathy determined by plasmin-alpha 2 plasmin inhibitor complexes in plasma. J Diabet Complicat. 1990;4:175-8.

20. Ohmoto K, Yamamoto S, Ideguchi S, Yamamoto R, Takatori K, Ohumi T, Hino K, Hirano Y. Clinical significance of thrombin-antithrombin III complex and plasmin-alpha 2 plasmin inhibitor complex in chronic liver diseases. Nihon Shokakibyo Gakkai Zasshi. 1990;87:1837-45.

21. Kawakami M, Kawagoe M, Harigai M, Hara M, Hirose T, Hirose W, Norioka K, Suzuki K, Kitani A, Nakamura H. Elevated plasma levels of alpha 2-plasmin inhibitor-plasmin complex in patients with rheumatic diseases. Possible role of fibrinolytic mechanism in vasculitis. Arthritis Rheum. 1989;32:1427-33.

22. Jinnin M, Ihn H, Yamane K, Asano Y, Yazawa N, Tamaki K. Plasma plasminalpha2-plasmin inhibitor complex levels are increased in systemic sclerosis patients with pulmonary hypertension. Rheumatology (Oxford). 2003;42: 240-3.

23. Kanno $Y$. The role of fibrinolytic regulators in vascular dysfunction of systemic sclerosis. Int J Mol Sci. 2019;20:E619.

24. Kanno Y, Kawashita E, Minamida M, Kaneiwa A, Okada K, Ueshima S, Matsuo $\mathrm{O}$, Matsuno $\mathrm{H}$. alpha2-antiplasmin is associated with the progression of fibrosis. Am J Pathol. 2010;176:238-45.
25. Kanno Y, Shu E, Kanoh H, Seishima M. The antifibrotic effect of a2AP neutralization in systemic sclerosis dermal fibroblasts and mouse models of systemic sclerosis. J Invest Dermatol. 2016;136:762-9.

26. Kanno Y, Kawashita E, Kokado A, Okada K, Ueshima S, Matsuo O, Matsuno H. Alpha2-antiplasmin regulates the development of dermal fibrosis in mice by prostaglandin F2a synthesis through adipose triglyceride lipase/calciumindependent phospholipase A2. Arthritis Rheum. 2013;65:492-502.

27. Bauman KA, Wettlaufer SH, Okunishi K, Vannella KM, Stoolman JS, Huang SK, Courey AJ, White ES, Hogaboam CM, Simon RH, Toews GB, Sisson TH, Moore BB, Peters-Golden M. The antifibrotic effects of plasminogen activation occur via prostaglandin E2 synthesis in humans and mice. J Clin Invest. 2010;120:1950-60.

28. Hattori N, Mizuno S, Yoshida Y, Chin K, Mishima M, Sisson TH, Simon RH, Nakamura T, Miyake $M$. The plasminogen activation system reduces fibrosis in the lung by a hepatocyte growth factor-dependent mechanism. Am J Pathol. 2004;164:1091-8.

29. Kanno Y, Kuroki A, Okada K, Tomogane K, Ueshima S, Matsuo O, Matsuno H. alpha2-Antiplasmin is involved in the production of transforming growth factor beta1 and fibrosis. J Thromb Haemost. 2007:5:2266-73.

30. Kida $T$, Seno $T$, Nagahara $H$, Inoue T, Nakabayashi A, Kukida Y, Fujioka K, Fujii W, Wada M, Kohno M, Kawahito Y. Roles of high-mobility group box 1 and thrombin in murine pulmonary fibrosis and the therapeutic potential of thrombomodulin. Am J Physiol Lung Cell Mol Physiol. 2018; 314:L473-83.

31. Wang Q, Wang J, Wang J, Hong S, Han F, Chen J, Chen G. HMGB1 induces lung fibroblast to myofibroblast differentiation through NF-kB-mediated TGF-b1 release. Mol Med Rep. 2017;15:3062-8.

32. Bangert A, Andrassy M, Müller AM, Bockstahler M, Fischer A, Volz CH, Leib C, Göser S, Korkmaz-Icöz S, Zittrich S, Jungmann A, Lasitschka F, Pfitzer G, Müller OJ, Katus HA, Kaya Z. Critical role of RAGE and HMGB1 in inflammatory heart disease. Proc Natl Acad Sci U S A. 2016;113:E155-64.

33. Li LC, Gao J, Li J. Emerging role of HMGB1 in fibrotic diseases. J Cell Mo Med. 2014;18:2331-9.

34. O'Reilly S. Toll like receptors in systemic sclerosis: an emerging target. Immunol Lett. 2018;195:2-8.

35. Yamashita T, Asano Y, Taniguchi T, Nakamura K, Saigusa R, Miura S, Toyama T, Takahashi T, Ichimura Y, Yoshizaki A, Trojanowska M, Sato S. Glycyrrhizin ameliorates fibrosis, vasculopathy, and inflammation in animal models of systemic sclerosis. J Invest Dermatol. 2017;137:631-40.

36. Kanno $Y$, Into T, Lowenstein CJ, Matsushita K. Nitric oxide regulates vascular calcification by interfering with TGF-b signalling. Cardiovasc Res. 2008;77: 221-30.

37. Kanno Y, Kaneiwa A, Minamida M, Kanno M, Tomogane K, Takeuchi K, Okada K, Ueshima S, Matsuo O, Matsuno $H$. The absence of uPAR is associated with the progression of dermal fibrosis. J Invest Dermatol. 2008; 128:2792-7.

38. Kanno Y, Sakai A, Miyashita M, Tsuchida K, Matsuo O. Plasminogen deficiency is associated with improved glucose tolerance, and lower DPP-4 activity. Diabetes Res Clin Pract. 2016;120:190-3.

39. Kanno Y, Ishisaki A, Miyashita M, Matsuo O. The blocking of UPAR suppresses lipopolysaccharide-induced inflammatory osteoclastogenesis and the resultant bone loss through attenuation of integrin b3/Akt pathway. Immun Inflamm Dis. 2016:4:338-49.

40. Kanno Y, Maruyama C, Matsuda A, Ishisaki A. uPA-derived peptide, Å 6 is involved in the suppression of lipopolysaccaride-promoted inflammatory osteoclastogenesis and the resultant bone loss. Immun Inflamm Dis. 2017;5: 289-99.

41. Kim J, Park JC, Lee MH, Yang CE, Lee JH, Lee WJ. High-mobility group box 1 mediates fibroblast activity via RAGE-MAPK and NF-KB signaling in keloid scar formation. Int J Mol Sci. 2017:19:E76.

42. Lee CC, Wang CN, Lee YL, Tsai YR, Liu JJ. High mobility group box 1 induced human lung myofibroblasts differentiation and enhanced migration by activation of MMP-9. PLoS One. 2015;10:e0116393.

43. Deane R, Singh I, Sagare AP, Bell RD, Ross NT, LaRue B, Love R, Perry S, Paquette N, Deane RJ, Thiyagarajan M, Zarcone T, Fritz G, Friedman AE, Miller BL, Zlokovic BV. A multimodal RAGE-specific inhibitor reduces amyloid b-mediated brain disorder in a mouse model of Alzheimer disease. J Clin Invest. 2012:122:1377-92

44. Li Z, Xu X, Feng X, Murphy PM. The macrophage-depleting agent clodronate promotes durable hematopoietic chimerism and donor-specific skin allograft tolerance in mice. Sci Rep. 2016;6:22143. 
45. Pattanaik D, Brown M, Postlethwaite BC, Postlethwaite AE. Pathogenesis of systemic sclerosis. Front Immunol. 2015;6:272.

46. Raker V, Haub J, Stojanovic A, Cerwenka A, Schuppan D, Steinbrink K. Early inflammatory players in cutanous fibrosis. J Dermatol Sci. 2017;87: 228-35.

47. Musumeci D, Roviello GN, Montesarchio D. An overview on HMGB1 inhibitors as potential therapeutic agents in HMGB1-related pathologies. Pharmacol Ther. 2014;141:347-57.

48. Helene M, Lake-Bullock V, Zhu J, Hao H, Cohen DA, Kaplan AM. T cell independence of bleomycin-induced pulmonary fibrosis. J Leukoc Biol. 1999;65:187-95

49. Yamamoto T, Nishioka K. Animal model of sclerotic skin. IV: induction of dermal sclerosis by bleomycin is T cell independent. J Invest Dermatol. 2001;117:999-1001.

50. Lotze MT, Tracey KJ. High-mobility group box 1 protein (HMGB1): nuclear weapon in the immune arsenal. Nat Rev Immunol. 2005;5:331-42.

51. Tian S, Zhang L, Tang J, Guo X, Dong K, Chen SY. HMGB1 exacerbates renal tubulointerstitial fibrosis through facilitating M1 macrophage phenotype at the early stage of obstructive injury. Am J Physiol Renal Physiol. 2015;308: F69-75.

52. Son M, Porat A, He M, Suurmond J, Santiago-Schwarz F, Andersson U, Coleman TR, Volpe BT, Tracey KJ, Al-Abed Y, Diamond B. C1q and HMGB1 reciprocally regulate human macrophage polarization. Blood. 2016;128: 2218-28.

53. Huber R, Meier B, Otsuka A, Fenini G, Satoh T, Gehrke S, Widmer D, Levesque MP, Mangana J, Kerl K, Gebhardt C, Fujii H, Nakashima C, Nonomura Y, Kabashima K, Dummer R, Contassot E, French LE. Tumour hypoxia promotes melanoma growth and metastasis via High Mobility Group Box-1 and M2-like macrophages. Sci Rep. 2016;18:29914.

54. Cui J, Wu X, Song Y, Chen Y, Wan J. Complement C3 exacerbates rena interstitial fibrosis by facilitating the $\mathrm{M} 1$ macrophage phenotype in a mouse model of unilateral ureteral obstruction. Am J Physiol Renal Physiol. 2019; 317:F1171-82

55. Nakayama W, Jinnin M, Makino K, Kajihara I, Makino T, Fukushima S, Inoue Y, Ihn H. Serum levels of soluble CD163 in patients with systemic sclerosis. Rheumatol Int. 2012;32:403-7.

56. Hasegawa M, Fujimoto M, Kikuchi K, Takehara K. Elevated serum levels of interleukin 4 (IL-4), IL-10, and IL-13 in patients with systemic sclerosis. J Rheumatol. 1997;24:328-32

57. Mojiri-Forushani H, Hemmati AA, Khodadadi A, Rashno M. Valsartan attenuates bleomycin-induced pulmonary fibrosis by inhibition of NF-kB expression and regulation of Th1/Th2 cytokines. Immunopharmacol Immunotoxicol. 2018;40:225-31.

58. Luzina IG, Keegan AD, Heller NM, Rook GA, Shea-Donohue T, Atamas SP. Regulation of inflammation by interleukin-4: a review of "alternatives". J Leukoc Biol. 2012;92:753-64.

59. Sempowski GD, Beckmann MP, Derdak S, Phipps RP. Subsets of murine lung fibroblasts express membrane-bound and soluble IL-4 receptors. Role of IL-4 in enhancing fibroblast proliferation and collagen synthesis. J Immunol. 1994;152:3606-14.

60. Jenkins SJ, Ruckerl D, Cook PC, Jones LH, Finkelman FD, van Rooijen N, MacDonald AS, Allen JE. Local macrophage proliferation, rather than recruitment from the blood, is a signature of $\mathrm{TH} 2$ inflammation. Science. 2011;332:1284-8.

61. Jenkins SJ, Ruckerl D, Thomas GD, Hewitson JP, Duncan S, Brombacher F, Maizels RM, Hume DA, Allen JE. IL-4 directly signals tissue-resident macrophages to proliferate beyond homeostatic levels controlled by CSF-1. J Exp Med. 2013;210:2477-91.

62. Groves AM, Johnston CJ, Misra RS, Williams JP, Finkelstein JN. Effects of IL-4 on pulmonary fibrosis and the accumulation and phenotype of macrophage subpopulations following thoracic irradiation. Int J Radiat Biol. 2016;92:754-65

63. Lin JX, Migone TS, Tsang M, Friedmann M, Weatherbee JA, Zhou L, Yamauchi A, Bloom ET, Mietz J, John S. The role of shared receptor motifs and common Stat proteins in the generation of cytokine pleiotropy and redundancy by IL-2, IL-4, IL-7, IL-13, and IL-15. Immunity. 1995;2:331-9.

64. Kim MJ, Lee YJ, Yoon YS, Lim JH, Park EM, Chong YH, Kang JL. A STAT6 inhibitor AS1517499 reduces preventive effects of apoptotic cell instillation on bleomycin-induced lung fibrosis by suppressing PPARy. Cell Physiol Biochem. 2018;45:1863-77.
65. Yan J, Zhang Z, Yang J, Mitch WE, Wang Y. JAK3/STAT6 stimulates bone marrow-derived fibroblast activation in renal fibrosis. J Am Soc Nephrol. 2015;26:3060-71.

\section{Publisher's Note}

Springer Nature remains neutral with regard to jurisdictional claims in published maps and institutional affiliations.
Ready to submit your research? Choose BMC and benefit from:

- fast, convenient online submission

- thorough peer review by experienced researchers in your field

- rapid publication on acceptance

- support for research data, including large and complex data types

- gold Open Access which fosters wider collaboration and increased citations

- maximum visibility for your research: over $100 \mathrm{M}$ website views per year

At BMC, research is always in progress.

Learn more biomedcentral.com/submissions 